\title{
POR UMA AGENDA POSITIVA DOS DIREITOS SEXUAIS DA ADOLESCÊNCIA
}

\author{
Maria Luiza Heilborn*
}

\section{Resumo}

$\mathrm{O}$ artigo busca esclarecer as dimensóes dos chamados direitos sexuais de adolescentes com base em perspectivas empíricas, tanto qualitativas quanto quantitativas. A partir de entrevistas em profundidade e um inquérito domiciliar com jovens sobre conhecimento, experiências e valores associados à sexualidade, o artigo procura demonstrar que a "conversa sobre sexo" é limitada no âmbito da família, da escola e nos serviços de saúde. O acesso à informação e familiaridade com a temática da sexualidade constitui-se em um direito sexual de primeira linha para adolescentes e jovens, a despeito das convicçóes morais do entorno social.

Palavras-chaves: adolescência; sexualidade; direitos sexuais; pesquisa empírica.

\begin{abstract}
For A POSITIVE AGENDA OF SEXUAL RIGHTS OF ADOLESCENTS

This article focuses on the theme of adolescent sexual rights, based on qualitative and quantitative empirical data. Taking into consideration the results obtained with deep interviews and a population survey with youth about knowledge, experience and values about sexuality, the article shows that "talking about sex" is still limited in different social spheres, that is, family, school and health services. The access to information and approach to sexual themes is a fundamental right to adolescents and youth, despite moral convictions that exist in the social environment.
\end{abstract}

Keywords: adolescence; sexuality; sexual rights; empirical research.

* Instituto de Medicina Social, Centro Latino-Americano em Sexualidade e Direitos Humanos (CLAM), UERJ, Rio de Janeiro, RJ, Brasil. E-mail: heilborn@ims.uerj.br. 


\section{Introdução}

Para os praticantes do ofício das ciências sociais, desnaturalizar categorias de pensamento de uma dada sociedade é a tarefa mais urgente. Já é bastante conhecido o esforço de desconstrução de categorias do nosso cotidiano que pareciam revelar evidências inquestionáveis. Por exemplo, os termos que designam as etapas da vida têm sido objeto de um exame constante para demonstrar seu caráter de invençáo: infância (Ariès, 1978); adolescência; juventude (Galland, 1997). Os marcos etários que delimitam as fronteiras entre as fases do ciclo de vida ou categorias de idade são móveis e variam de acordo com as concepçóes sociais acerca do humano e das relaçóes intergeracionais de um dado momento histórico.

Adolescência e juventude são invenções culturais historicamente datadas e guardam, hoje em dia, resquícios das formulaçóes eruditas e comuns, construídas ao longo dos séculos XIX e XX (Vincent-Buffault, 1996). Em nossa sociedade, as representaçóes correntes sobre adolescência carregam estereótipos como "fase problemática da vida", cuja principal leitura é a noção de "crise". Juventude encerra uma acepçáo de tempo ideal, no qual a incerteza de projetos é admissível e o futuro ainda aguarda definição. Nessa mirada, a juventude funciona como um termômetro de possíveis mudanças sociais, pois é percebida como a geração responsável pela transmissão de valores ou pela ruptura de determinados padróes. Desse modo, ela pode ser tomada como responsável pela disrupção de mecanismos que presidem a integração social e com frequência é analisada a partir da ótica de "problema social" quando se afasta das expectativas sociais nela depositadas (Abramo, 1997). Para essa representação de adolescência e juventude concorrem contribuiçóes científicas do início do século XX, tal como da psicologia e da psicanálise, que difundem uma ótica naturalista fundada em definições universais e atemporais (Brandão, 2003, pp. 57-58). Essas duas disciplinas/saberes ajudaram sobremaneira a erigir a representaçáo hegemônica acerca da adolescência como fase sujeita às perturbaçôes. Os saberes psi não estão à margem da biomedicina, que com seu exame minucioso do organismo humano define parâmetros orgânicos de um amadurecimento do ser e ajuda a criar no processo vital marcas "indeléveis" das fases da vida com ingênua desconsideração das condições sociais que as produzem, redefinem, espremem ou alongam-nas.

Uma alternativa sociológica interessante para a abordagem da adolescência é oferecida pela linhagem de trabalhos contemporâneos que propóe o entendimento da questão como processo social de passagem ou entrada na vida 
adulta (Galland, 1997). Essa perspectiva recusa a definição de marcos etários para circunscrever esta etapa da vida e enfatiza os processos subjacentes como elementos característicos dessa fase. $\mathrm{O}$ conceito de trajetória biográfica é central para a análise dessa transição. A passagem para a vida adulta não pode ser reduzida ao desenvolvimento psicológico como muitos propugnam: ela modela a condição do ser adulto ao se apresentar distinta segundo as diferentes condiçōes materiais de existência e os diferenciais de gênero e de raça/cor que condicionam as trajetórias juvenis. $\mathrm{O}$ conceito permite reunir na análise o entrecruzamento entre os diferentes eixos de classificação/hierarquização social que designam espaços sociais possíveis (na acepção de horizontes de possibilidades) para os sujeitos.

Um conjunto de pequenos rituais de passagem constitui o processo de transição para a vida adulta. A adolescência/juventude é a etapa da vida em que representaçóes, valores, práticas, papéis e condutas sociais são consolidados. Neste sentido, um elenco de pequenas e sucessivas experiências de primeira vez modula a socialização do jovem (Bozon, 2003; Giami \& Schiltz, 2004) tal como o primeiro namoro, a primeira relação sexual e o primeiro trabalho.

\section{Sexualidade, corpo e idades}

A sexualidade é aqui compreendida como produto de distintos cenários e não deriva primariamente do funcionamento biopsíquico dos sujeitos. Antropólogos e sociólogos consideram que o exercício da sexualidade se dá em contextos sociais muito precisos, o que orienta a experiência e a expressão do desejo, das emoçóes, das condutas e práticas corporais. Essa ênfase nos cenários socioculturais alude à premissa de que as características distintas entre os homens e mulheres no tocante à vida sexual e na interface desta com a esfera reprodutiva resultam de uma combinação de fenômenos que reverberam nos corpos como efeito de processos complexos de socialização dos gêneros. Desse modo, os processos de aprendizagem cultural em torno da sexualidade estão intimamente relacionados aos códigos de gênero vigentes no contexto social em que os sujeitos estão inseridos. Há, assim, um inextricável e inescapável imbricamento entre gênero e sexualidade. Também as idades consideradas adequadas para a expressão da sexualidade dependem de convenções sociais variáveis.

A sexualidade é um dos principais domínios que incitam o jovem a criar uma esfera de autonomia individual, o que se dá, sobretudo, pela passagem à 
sexualidade com parceiro. A construção desse espaço privado envolve o aprendizado de como se estabelece um relacionamento afetivo e sexual. A entrada na sexualidade com parceiro depende de uma contínua decifração de códigos de conduta, de gestos e de leitura das intençóes dos envolvidos, de negociação de significados (Berger \& Kellner, 1970) para que de fato tenha lugar. Trata-se de um processo de aproximaçáo que implica: "reconhecer o significado de estados internos, organizar a sequencia dos atos especificamente sexuais, decodificar situações, estabelecer limites nas respostas sexuais e vincular significados de aspectos náo sexuais da vida para a experiência sexual propriamente dita" (Gagnon $\&$ Simon, $1973 / 2005$, p. 13). Tal aprendizado compreende um processo de experimentação pessoal e de impregnação pela cultura do grupo, que se acelera na adolescência/juventude. "A autonomia progressiva frente à família expõe fortemente os jovens à cultura do grupo de pares" (Heilborn et al., 2002, p. 23). Colegas e amigos se tornam fortes referências de validaçáo e reconhecimento dos sujeitos e, cada vez mais, desempenham um papel expressivo na modelação de suas condutas. A família perde relativamente importância frente à opinião de outros jovens com quem o adolescente convive. Contudo, ela é um importante agente de informação sobre sexualidade para crianças, adolescentes e jovens. No inquérito GRAVAD ${ }^{1}$ verificou-se que em muitos grupos sociais as relaçóes entre pais/mães e filhos (as) são travadas por concepçóes que definem que sexualidade não é assunto para se conversar abertamente, pois comprometeria o respeito entre as geraçóes.

O caráter de aprendizado das interaçóes amorosas e sexuais não é retido pela consciência; ele é de tal forma interiorizado que determinadas atitudes são interpretadas como espontâneas (o jargão "a gente já nasce sabendo"), embora tenham estado presentes no horizonte de possibilidades há certo tempo, de modo que é quase improvável que não se tenha pensado no assunto. A experimentação do corpo em contatos afetivo-sexuais na adolescência integra hoje em dia a socialização comum dos jovens brasileiros.

\section{Interaçóes amorosas na adolescência}

$\mathrm{Na}$ sociedade brasileira, uma das formas de interação afetiva que pode desembocar em relações sexuais é o namoro. Trata-se de uma relaçáo de exclusividade entre dois parceiros, que requer em geral ser comunicada para amigos e familiares. Existe uma forte codificação das interações sociossexuais entre jovens e uma repartição de atitudes esperadas segundo o gênero (Bozon \& Heilborn, 
2006). Como toda relação social, esta forma de vínculo apresenta transformaçóes históricas. Há algumas décadas atrás, o namoro podia permanecer casto por bastante tempo: o homem estabeleceria a relação para depois solicitar favores que a mulher somente poderia conceder progressivamente. Os contatos corporais tornavam-se, com o tempo, mais íntimos e variados. Na versão tradicional do namoro, a penetração vaginal permanecia proibida a fim de preservar a virgindade da moça.

Modificaçóes recentes nos costumes sexuais no Brasil introduziram uma nova temporalidade da sexualização no namoro e em outras formas de relacionamento entre os jovens, como o ficar. O exercício de relaçóes sexuais no par se converteu em uma questão para rapazes e moças. Isto é, o namoro deixou de ser uma etapa preparatória para a conjugalidade e adquiriu uma realidade em si, como etapa de experimentaçáo afetiva e sexual para jovens de ambos os sexos. Um dos desdobramentos desse fenômeno foi a diminuição na idade de iniciação sexual das mulheres brasileiras (em torno de dois anos em duas décadas) $)^{2}$.

O ficar - modo de encontro ou de relacionamento - acelera a interação corporal entre os adolescentes e jovens. Este tipo de relaçáo ocorre em lugar público (festa, baladas, boate, bar); a atração dos indivíduos suscita um contato corporal imediato (beijos, carícias, até mesmo relação sexual), sem vínculo entre os parceiros, que, em geral se separam sem a perspectiva de reencontro (Rieth, 1998; Schuch, 1998).

Embora transformaçôes sociais contemporâneas tenham promovido mudanças nas convenções sexuais e em certa medida nas relações de gênero no Brasil, a cultura sexual no país continua marcada fortemente por uma categorizaçáo de gênero que reserva atitudes e qualidades contrastivas para homens e mulheres. $\mathrm{Na}$ construção do gênero feminino há uma subsunção do sexo à afetividade, frequentemente referida pela literatura socioantropológica como uma dimensão relacional do gênero feminino. Já a sexualidade nos homens é socialmente modelada no sentido de ser portadora de sentido em si mesma, como se retivesse uma intrínseca qualidade instrumental (Heilborn, 2004), sendo a disposição para a atividade sexual e a valorizaçâo do número de parceiros bons exemplos disso. Desse modo, masculinidade e atividade estão associadas, por oposição a feminilidade e passividade. Tal sistema classificatório ordena as relaçóes entre pessoas do mesmo sexo ou entre sexos "opostos", funcionando como um quadro de leitura para as condutas. Sobre os homens é exercida uma vigilância constante de seus gestos e comportamentos de maneira que sobre estes náo recaia sombra de dúvida sobre sua masculinidade. 
$\mathrm{Na}$ adolescência, há uma pressão para que o rapaz tenha relaçóes sexuais com pessoa do sexo oposto o quanto antes, de modo assegurar sua virilidade, espantando qualquer possível fantasma de homossexualidade. $\mathrm{O}$ masculino se compóe assim de imagens fortemente valorizadas, com o machão como um dos modelos da masculinidade hegemônica (Heilborn \& Carrara, 1998), e de imagens estigmatizadas, como o homossexual passivo ou efeminado ${ }^{3}$. As mulheres, por sua vez, devem administrar os avanços masculinos se quiserem assegurar a reputação de moça de família ou de mulher honesta. A perda da virgindade deixou de ser um atributo passível de estigmatização das mulheres, contudo continua a existir certa exigência de virgindade moral, que se apresenta sob a forma de um jeito passivo e ingênuo em matéria sexual, o que torna, por exemplo, difícil tratar questôes de sexualidade ou de contracepção com o parceiro.

Complementarmente, a maternidade é um componente muito valorizado da feminilidade, o que se traduz por um ideal presente na sociedade brasileira de ter o primeiro filho bastante jovem. Esse ideal traz implícito o de entrada na conjugalidade também relativamente cedo, evidenciado, por exemplo, pela recente construçáo da gravidez na adolescência como um grave problema social no país. A visibilidade adquirida pela questáo se deu no contexto de redução da fecundidade e de maior proporção de gravidez e de nascimento na juventude que ocorre fora de uma união conjugal (Longo \& Rios-Neto, 1998; Heilborn \& Cabral, 2006). A "novidade" atribuída a eventos de gravidez nesta etapa da vida e sua percepção como problema dá-se em parte por essa "ilegitimidade", que não é a única faceta da questão, mas contribui para transformá-la em um problema social. Os discursos sobre "gravidez precoce" frequentemente se referem a uma evolução negativa dos costumes e salienta um clima de erotização precoce indesejável (muitas vezes atribuído à mídia), irresponsabilidade dos jovens, ignorância, falta de autoridade dos pais e ausência de diálogo entre geraçôes. As mulheres continuam sendo culpabilizadas por engravidar fora do casamento; os homens, absolvidos ou esquecidos de sua participação no evento.

Apesar das mudanças, persiste uma dinâmica de gênero tradicional no modo como se desenrolam as relaçóes sexuais, especialmente para os jovens: os homens pedem, as mulheres respondem de diversas maneiras ao ceder, recusar ou temporizar os desejos do parceiro. As convençóes culturais internalizadas pela socialização de gênero e as atitudes prescritas na esfera sexual tornam difícil para as mulheres se prepararem para uma primeira relação sexual protegida, pois isto implicaria um tipo de previsão e, portanto, uma postura ativa diante do sexo, 
podendo deixar entender que elas são "experientes", o que levantaria suspeitas quanto a sua moralidade.

A sociedade brasileira, acompanhando mudanças generalizadas no que concerne à sexualidade, viu aumentar a tolerância com temas antes considerados limite da moralidade sexual tais como a masturbação, o adultério, a prostituição, a pornografia e a diversidade de preferências e identidades sexuais. Nesse contexto, entretanto, novos demarcadores do maldito e do ilícito se presentificaram: o turismo sexual e a pedofilia. Esses novos objetos de pânico moral integram-se em um quadro que vem paulatinamente admitindo a concepção de direitos humanos ligados à esfera da sexualidade.

\section{Sexualidade adolescente: entre pânico moral e problema social}

As interações sexuais entre homens e mulheres são vividas, na cultura brasileira, como fruto da espontaneidade (Heilborn \& Cabral, 2006). Muitas vezes, o intercurso sexual é barganhado pelos rapazes como "prova de amor" por parte de suas parceiras. Pode-se assim aventar as dificuldades materiais e simbólicas que revestem a utilização da contracepção por mulheres jovens. Assim, diferentemente do tom acusatório predominante em relação às adolescentes e jovens que iniciam sua vida sexual, é necessário avaliar o cenário social que simultaneamente estimula o exercício da sexualidade como um caminho de autonomia e que interdita a discussão social aberta sobre contracepção para tais moças.

Este panorama impõe a indagação sobre o conteúdo dos direitos sexuais dos adolescentes. Os direitos sexuais de adolescentes têm sido entendidos por setores sociais preocupados com uma excessiva emancipação dos filhos relativamente aos pais como uma espécie de incentivo à liberalidade sexual. Tal percepção faz com que, genericamente, entenda-se como problemática a exposição precoce desses jovens a riscos tidos por inerentes à sexualidade. Ora, uma perspectiva abrangente dos direitos inclui o do acesso à informação qualificada sobre sexualidade. Trata-se, portanto, de entender que a informação sobre sexualidade náo depende exclusivamente da família. Esse direito deve ser provido no âmbito da escola e dos serviços de Saúde que atendam população na faixa etária em debate.

Uma perspectiva adequada quanto à informação deve centrar-se na compreensão de que a sexualidade náo se reduz a explicação do amadureci- 
mento sexual orgânico, pois abrange a compreensão dos cenários relacionais da mesma, que importam em relaçóes de gênero, em reconhecer o desejo ou não de estabelecer intimidade corporal com alguém, capacidade de refletir sobre as convençóes sexuais e proteger-se tanto da eventualidade reprodutiva como de potenciais infecçóes sexualmente transmissíveis. Na pesquisa GRAVAD se constatou que, entre jovens de ambos os sexos, nas primeiras informaçóes obtidas sobre sexualidade a condição de classe e, em especial, o nível de escolaridade da mãe tinham significativo impacto no modo como se dava a entrada dos jovens na sexualidade com parceiro. A maior quantidade de informaçóes sobre o tema tornava mais segura uma prevenção da gravidez ou de DSTs (Bozon \& Heilborn, 2006). Nesse inquérito domiciliar (Heilborn, Aquino, Bozon \& Knauth, 2006) com 4.634 jovens de ambos os sexos entre 18 e 24 anos, com uma técnica rememorativa sobre suas vivências na adolescência, perguntou-se sobre a socialização para a sexualidade, fonte de informação e formas de controle dos pais/adultos sobre seus relacionamentos de amizade e namoro. Os jovens mais abastados contavam com informaçóes mais sólidas sobre a vida sexual e compartilhavam de uma visão de mundo em que a sobrevinda eventual de um filho - fruto de uma relaçáo sexual desprotegida - poderia comprometer seus esforços de escolarização e entrada no mercado de trabalho mais bem preparados. Já para os mais pobres, a ausência de qualquer perspectiva escolar ou profissional, ligada a uma escolaridade bastante irregular, faz com que os sujeitos considerem uma eventual gravidez como perturbaçáo menor e, portanto, náo os leva a tentar evitá-la. Desse modo, observa-se que a chamada "ignorância ou irresponsabilidade" das jovens decorre de situaçóes socialmente enquadradas como ausência de projetos de vida, intimamente relacionada à fragilidade da formação escolar. Desse modo, ainda que a escola apresente tantas deficiências para a formação das crianças e adolescente, é imperativo imaginar que a socialização no que toca à sexualidade está presente em seu universo e cabe a ela, como a outras agências, promover a educação em sexualidade.

Afetividade e sexualidade enquanto dimensôes da pessoa envolvem complexos processos de aprendizagem sociocultural e se atualizam cotidianamente através das formas sociais culturalmente convencionadas. $\mathrm{O}$ exercício da sexualidade pode encarnar a vontade de procriar, a satisfação do desejo, a demonstração de um estatuto social, ou um gesto que consolida uma relação afetiva. Estes diversos significados não são necessariamente excludentes, podendo haver um constante ajuste dos sujeitos em função do momento da trajetória biográfica (Spira, Bajos \& le Groupe ACSF, 1993, p. 34). A atividade 
sexual não é uma prática autonomizada, está sempre inscrita em um conjunto mais amplo de significaçóes, que agrupam desde o contexto relacional específico e o momento da trajetória de vida até o tipo de parceria e afetos envolvidos. As adolescentes retratadas na pesquisa GRAVAD exemplificam tal multiplicidade de sentidos.

A adolescência/juventude é comumente vista como um período da vida em que se intensifica o processo de construção da autonomia dos jovens diante da família e a busca de suas singularidades. Nessa fase, representaçóes, valores e comportamentos relativos à sexualidade e aos papéis de gênero são consolidados, na medida em que rapazes e moças começam a experimentar relações afetivas que ampliam seu universo de vínculos para além da parentela e da rede de amigos. As interaçóes afetivas e sexuais, como as demais formas de interação social, apresentam-se pautadas por códigos entre os atores sociais, que por sua vez estáo submetidos a expectativas sociais de desempenho segundo o sexo e o gênero. As relações de gênero encarnam formas desiguais de poder que assumem modulações específicas em cada esfera da vida e contexto social. Assim, o aprendizado em torno da sexualidade está intimamente relacionado ao modo como estão organizadas as relaçóes de gênero nos contextos socioculturais em que os indivíduos encontram-se inseridos. Por isso, o exame das interaçóes entre os gêneros permite desvendar os roteiros preestabelecidos que orientam as condutas individuais na medida em que se impóe em duas instâncias: como forma de classificação ordenadora do mundo social, exteriorizada em estruturas objetivas, e como instância interiorizada que constitui a identidade do sujeito.

Como se conectam problema social e pânico moral? Já demonstramos que problemas sociais necessitam de um determinado contexto de produção de sentidos que postulam a urgência em transformar a realidade. Atores sociais vocalizam possibilidades de alterar o status quo, promovendo versóes sobre a origem e possíveis horizontes futuros das ditas condiçóes. Quando se trata da sexualidade adolescente, imbricada no fenômeno da gravidez dita precoce, desenha-se um imaginário de tintas dramáticas sobre a erotização de pessoas consideradas muito jovens, associada com frequência com o que é qualificado como desestruturação familiar. O pânico moral infiltra-se nos interstícios do discurso do problema social. Por tal termo, entendemos as ansiedades geradas pelas práticas sexuais no âmbito da moralidade (Vance, 1995; Rubin, 1975). Produz-se um diagnóstico de problema social - no caso, a reprodução precoce que compromete o futuro escolar e profissional dos jovens - no qual a moralidade passa a deter caráter salvacionista, preventivista de um futuro debate social. 


\section{Consideraçóes finais}

Os direitos sexuais de adolescentes têm sido entendidos por setores sociais preocupados com uma excessiva emancipação dos filhos relativamente aos pais como uma espécie de incentivo à liberalidade sexual. Tal percepção faz com que, genericamente, entenda-se como problemática a exposição precoce desses jovens a riscos tidos por inerentes à sexualidade. Ora, uma perspectiva abrangente dos direitos inclui o do acesso à informação qualificada sobre sexualidade. Trata-se, portanto, de entender que a informação sobre sexualidade não depende exclusivamente da família. Esse direito deve ser provido no âmbito da escola e dos serviços de Saúde que atendam população na faixa etária em debate.

Assim, uma perspectiva adequada na abordagem da temática da sexualidade juvenil deve centrar-se na compreensão de que a sexualidade não se reduz à explicação do amadurecimento sexual orgânico, pois abrange a compreensão dos cenários relacionais da mesma que importam em relações de gênero, em reconhecer o desejo ou não de estabelecer intimidade corporal com alguém, capacidade de refletir sobre as convençóes sexuais e proteger-se tanto da eventualidade reprodutiva como de potenciais infecçôes sexualmente transmissíveis.

\section{Referências}

Abramo, H. W. (1997). Consideraçôes sobre a tematização social da juventude no Brasil. Revista Brasileira de Educação, número especial: Juventude e Contemporaneidade, 6, 25-36.

Ariès, P. (1978). História social da criança e da família. Rio de Janeiro: Zahar.

Berger, P. \& Kellner, H. (1970). Marriage and the construction of reality. In: P. H. Dreiazel (org.). Recent sociology. Nova York: The Mac Millow Company.

Bozon, M. (2003). A quel âge les femmes et les hommes commencent-ils leur vie sexuelle? Comparaisons mondiales et évolutions récentes. Population et Sociétés, 391, 4-8.

Bozon, M. \& Heilborn, M. L. (2006). Iniciação à sexualidade: modos de socialização, interações de gênero e trajetórias individuais. In: M. L. Heilborn et al. (orgs.). O aprendizado da sexualidade: reprodução e trajetórias sociais de jovens brasileiros (pp. 156-211). Rio de Janeiro: Fiocruz.

Brandão, E. R. (2003). Individualização e vínculo familiar em camadas médias: um olhar através da gravidez na adolescência. (Tese de Doutorado em Saúde Coletiva. Rio de Janeiro, Instituto de Medicina Social/Universidade do Estado do Rio de Janeiro). 
Galland, O. (1997). Sociologie de la jeunesse. Paris: Armand Colin.

Gagnon, J. \& Simon, W. (1973). Sexual conduct: the social sources of human sexuality. Chicago: Aldine, 2005.

Giami, A. \& Schiltz, M. A. (orgs.). (2004). L'expérience de la sexualité chez de jeunes adultes. Entre errance et conjugalité. Paris: Inserm (Institut National de la Santé et de la Recherche Médicale).

Heilborn, M. L. (2004). Dois é par: gênero e identidade sexual em contexto igualitário. Rio de Janeiro: Garamond.

Heilborn, M. L. \& Carrara, S. (1998). Em cena os homens... Estudos feministas, 6(2), $370-4$.

Heilborn, M. L., Salem, T., Bozon, M., Aquino, E., Knauth, D., Rohden, F., Victora, C., Mccallum, C. \& Brandão, E. (2002). Aproximaçôes sócio-antropológicas sobre a gravidez na adolescência. Horizontes Antropológicos, 7(17), 13-45.

Heilborn, M. L. \& Cabral, C. S. (2006). Parentalidade juvenil: transição condensada para a vida adulta. In: A. A. Camarano (org.). Transição para a vida adulta ou vida adulta em transição? (pp. 225-256). Rio de Janeiro: IPEA.

Heilborn M. L., Aquino, E. M. L., Bozon, M. \& Knauth, D. R. (orgs.). (2006). O aprendizado da sexualidade: reprodução e trajetórias sociais de jovens brasileiros. Rio de Janeiro: Garamond/Fiocruz.

Longo, L. F. B. \& Rios-Neto, E. (1998). Virgindade matrimonial e iniciação sexual: uma análise temporal. In: XI Encontro Nacional de Estudos Populacionais. Caxambu, ABEP. Disponível em <http://www.abep.nepo.unicamp.br/docs/anais/PDF/1998/a131.pdf>. Recuperado em outubro de 2003.

Rieth, F. (1998). Ficar e namorar. In: C. Bruschini \& H. B. de Hollanda (orgs.). Horizontes plurais: novos estudos de gênero no Brasil. São Paulo: Ed. 34.

Rubin, G. (1975). The traffic in women. Notes on the "political economy" of sex. In: R. Reiter (ed.). Toward an Anthropology of Women (pp. 157-210). New York: Monthly Review Press.

Schuch, P. (1998). Caricias, olhares e palavras: uma etnografia sobre o "ficar" entre jovens universitários de Porto Alegre. (Dissertação de Mestrado em Antropologia Social. Porto Alegre, Instituto de Filosofia e Ciências Humanas/Universidade Federal do Rio Grande do Sul).

Spira, A., Bajos, N. \& le Groupe ACSF. (1993). Les comportements sexuels en France. Paris: La Documentation Française.

Vance, C. (1995). A antropologia redescobre a sexualidade: um comentário teórico. Physis: Revista de Saúde Pública, 5(1), 7-31.

Vincent-Buffault, A. (1996). Da amizade: uma história do exercício da amizade nos séculos XVIII e XIX. Rio de Janeiro: Jorge Zahar. 


\section{Notas}

${ }^{1}$ A pesquisa Gravad ("Gravidez na adolescência: estudo multicêntrico sobre jovens, sexualidade e reprodução no Brasil”) é investigaçáo sobre comportamentos sexuais e reprodutivos de jovens brasileiros constituída por duas etapas: uma inicial, qualitativa, em que foram realizadas 123 entrevistas em profundidade entre 1999-2000, e outra, quantitativa, abrangendo 4.634 indivíduos em um inquérito populacional com amostra aleatória e estratificada levado a termo entre outubro de 2001 e janeiro de 2002. A pesquisa limitou-se a três grandes capitais, Porto Alegre, Rio de Janeiro e Salvador, situadas em regióes bem díspares do país (Sul, Sudeste e Nordeste). Em ambas as etapas foram entrevistados homens e mulheres entre $18 \mathrm{e}$ 24 anos, em entrevistas face a face, com o objetivo de investigar os comportamentos sexuais e reprodutivos de jovens brasileiros numa perspectiva biográfica. O estudo envolveu equipes de pesquisadores de diferentes instituiçóes, cujos coordenadores foram: Maria Luiza Heilborn (Instituto de Medicina Social da Universidade do Estado do Rio de Janeiro - IMS/UERJ); Michel Bozon (Institut National d'Études Démographiques - INED, Paris/França); Estela M. L. Aquino (Instituto de Saúde Coletiva da Universidade Federal da Bahia - MUSA/ISC/ UFBA) e Daniela Knauth (Núcleo de Pesquisa em Antropologia do Corpo e da Saúde da Universidade Federal do Rio Grande do Sul - NUPACS/UFRGS). A execução do estudo foi realizada por três centros de pesquisa: Programa em Gênero, Sexualidade e Saúde (IMS/ UERJ), Programa de Estudos em Gênero, Mulher e Saúde (MUSA/ISC/UFBA) e NUPACS (UFRGS).

${ }^{2}$ Observa-se, entretanto, que no Brasil a sexualização dos relacionamentos afetivos pré-maritais não implicou necessariamente uma atenção especial às questóes contraceptivas. Estas continuam sendo maciçamente preconizadas para mulheres com vida conjugal.

${ }^{3} \mathrm{Um}$ dos desdobramentos curiosos da paternidade precoce é justamente o efeito de afirmação da sexualidade dos jovens pelo fato de terem feito um filho em uma mulher e não pela paternidade em si, sobretudo entre os segmentos populares.

Recebido em 13 de dezembro de 2011 Aceito para publicação em 07 de abril de 2012 